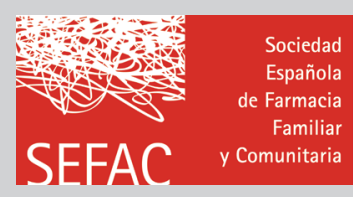

\title{
Día Mundial del Farmacéutico: una fecha para reivindicar una profesión global
}

\author{
Luis García Moreno \\ Farmacéutico comunitario. Presidente de SEFAC Castilla-La Mancha.
}

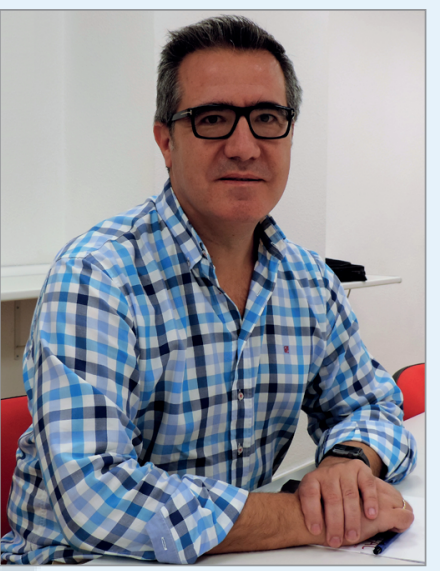

Luis García Moreno

\section{PALABRAS CLAVE}

Día Mundial del Farmacéutico, farmacia comunitaria, servicios profesionales farmacéuticos, dispensación, sistema sanitario, prestación farmacéutica

\section{ABREVIATURAS}

FIP: Federación Internacional Farmacéutica

\section{KEYWORDS}

World Pharmacists Day, community pharmacy, pharmaceutical services, dispensing, healthcare system, public pharmaceutical services

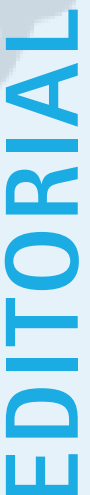

De la investigación a la asistencia sanitaria: el farmacéutico a su servicio. Este es el lema que ha escogido la Federación Internacional Farmacéutica (FIP) para celebrar este 25 de septiembre el Día Mundial del Farmacéutico. Un año más, instituciones de todo el mundo y profesionales farmacéuticos (más de 139 entidades y más de cuatro millones de profesionales, según datos de la FIP) nos sumamos a esta iniciativa que, en esta edición, quiere incidir en las numerosas aportaciones que la profesión farmacéutica hace a la salud, ya sea desde el desarrollo de medicamentos hasta los servicios profesionales farmacéuticos, pasando por la formación en las universidades o la atención farmacéutica.

La celebración de este Día es una magnífica ocasión para llamar la atención sobre la gran labor que desarrollan (desarrollamos) los farmacéuticos en sus (nuestros) diferentes ámbitos de actuación: investigación, docencia, promoción de la salud y salud pública, hospitales, distribución, análisis clínicos, industria y, cómo no, farmacia comunitaria, entre otros. No en vano, el farmacéutico es un profesional global, no solo por su presencia necesaria en todos los sistemas sanitarios que se precien, sino por su capacidad para desarrollar numerosas responsabilidades en áreas como las ya mencionadas, algo que lo convierte, sin duda, en uno de los profesionales de la salud más cualificados y con un contenido curricular más completo. Realmente pocos sanitarios pueden presumir de esto. Pese a ello no parece que el colectivo sea siempre suficientemente valorado como merecería. Francisco Martínez Romero, fundador de SEFAC, acostumbraba a preguntarse para qué sirve un farmacéutico y aunque parecería una pregunta retórica si tenemos en cuenta todos los desarrollos posibles que tiene la profesión, no lo es en absoluto y encierra también una compleja realidad, al menos en el campo de la farmacia comunitaria, que es el que más directamente nos toca. Esta realidad no es otra que el desconocimiento del enorme potencial que encierra en toda su dimensión nuestro colectivo o, dicho de otra manera, el poco provecho que se sacan de los conocimientos de los farmacéuticos en general y, en particular, de los comunitarios. De hecho, y por poner solo un ejemplo, hay grandes investigadores mundialmente reconocidos a los que se les suele citar como bioquímicos o con alguna de sus otras titulaciones pasando por alto su condición de farmacéuticos, como si la capacidad investigadora no fuera una virtud de esta profesión.

\section{Algo más que próximos $\mathrm{y}$ accesibles}

En el campo de la farmacia comunitaria, es de sobra conocida la idea de que los farmacéuticos somos los profesionales de la salud más próximos y accesibles a la población, gracias a una red de farmacias (cerca de 23.000) que garantiza un acceso de calidad, rápido y eficaz a la prestación farmacéutica y, en concreto, a la dispensación de medicamentos, especialmente en el medio rural y zonas con mucha dispersión poblacional (allá donde no queda médico queda un farmacéutico). No obstante, con esto no vale, pues esa "capilaridad" no es tanto del farmacéutico comunitario como del modelo, por lo que con esta premisa tenemos que demostrar que, como profesionales, estamos a la altura del citado modelo. No obstante, ¿es realmente consciente el conjunto de la sociedad y, en particular, la Administración de lo que esto significa? Más de dos millones de personas pasan diariamente por las farmacias españolas, sin embargo aún queda mucho por hacer si se quiere aprovechar al máximo las capacidades de los farmacéuticos comunitarios. El estudio Refcom. La realidad de la farmacia comunitaria en España, que recogió la opinión de la población general, farmacéuticos y pacientes sobre la actividad farmacéutica, señalaba que más de un 60 por ciento de la población consideraba que los conocimientos de los farmacéuticos no estaban suficientemente aprovechados en el sistema sanitario. 
Un dato realmente llamativo teniendo en cuenta, como mencionaba antes, la amplia formación que reciben los farmacéuticos en la universidad, por no hablar de la, cada vez más, imprescindible formación de postgrado. ¿Podemos permitirnos que profesionales formados durante años $-y$ que se siguen formando- en el medicamento y en materias tan complejas como la farmacología, la inmunología o la bioquímica, entre otras, no sean una punta de lanza más consistente en la atención sanitaria y sociosanitaria? Sobre todo si tenemos en cuenta un entorno caracterizado cada vez más por el envejecimiento, la cronificación de enfermedades, la polimedicación y la falta de adherencia terapéutica. ¿Acaso puede haber alguien más experto en medicamentos y que esté en más contacto con el paciente y sus familiares que un farmacéutico comunitario? Por tanto, la farmacia comunitaria es mucho más -o debe serlo- que un establecimiento próximo y accesible; es un caudal de conocimiento que, no obstante, tiene que trabajar más para transmitir una imagen asistencial y de centro sociosanitario (según también Refcom solo el 9 por ciento de la población nos ve como centros exclusivamente sanitarios). Ahí sí reside nuestra responsabilidad para disipar las dudas de aquellos que aún ven la farmacia comunitaria como algo ajeno o externo al Sistema Nacional de Salud y así poder anclarnos a este.

\section{Servicios profesionales}

A esto último -a cambiar esa percepción y aumentar la integración en las políticas sanitarias estratégicas- puede contribuir de manera decisiva la actual evolución en la que vive inmersa la farmacia comunitaria consistente de dejar de centrar la atención en el producto (medicamento) para centrarse en el conocimiento (el uso de la farmacoterapia por el paciente y cómo hacer que obtenga mejores resultados). Esta evolución lleva implícita la adquisición de nuevas competencias y habilidades enfocadas hacia la provisión de servicios profesionales farmacéuticos asistenciales que van mucho más allá de la tradicional, aunque no menos importante, dispensación y de otros servicios reconocibles como la indicación farmacéutica y el seguimiento farmacoterapéutico. Servicios como la revisión del uso de los medicamentos, la conciliación de la medicación, cesación tabáquica, la participación en cribados, la determinación de parámetros biológicos y un largo etcétera, tanto en el campo de los me- dicamentos como en el de la salud pública, son elementos que deben marcar el presente y el futuro más inmediato de la farmacia comunitaria para afianzar su posición y, como dice el lema del Día Mundial del Farmacéutico, seguir demostrando que el farmacéutico está siempre al servicio de las demandas y necesidades no solo de sus pacientes y de la población sino de la eficiencia del sistema sanitario. Muchos de estos servicios son todavía incipientes y poco conocidos por el conjunto de los pacientes. Trabajar en su protocolización, consensuarlos científicamente con otros colectivos sanitarios (como hace SEFAC con las sociedades científicas médicas) y difundirlos convenientemente acercándolos a la población (como desde nuestra Sociedad se viene llevando a cabo desde 2015 con las carpas de salud El farmacéutico que necesitas, cuyas próximas citas serán en octubre, primero en Albacete y después en Barcelona) son elementos indispensables para la extensión, valoración e inclusión de los servicios profesionales farmacéuticos en las carteras de prestaciones asistenciales de las Administraciones sanitarias.

La celebración del Día Mundial del Farmacéutico debe servir, pues, para reivindicar todo lo que nuestra profesión puede dar de sí, ya sea desde los laboratorios que investigan nuevas moléculas (la industria farmacéutica no solo es la que sustenta el grueso de las inversiones en investigación en España, sino también una de las pioneras en la aplicación de normas de calidad) hasta el cara a cara con el paciente, bien en el mostrador bien en la zona de atención personalizada. Todo ello sin obviar el resto de posibilidades, menos conocidas (distribución mayorista a la cabeza de Europa tecnológicamente, análisis de aguas para la salud pública, botánica, medicamentos veterinarios y tantas otras opciones).

En definitiva, pocos profesionales de la salud han prestado y prestan un servicio tan amplio y de tanta calidad como los farmacéuticos comunitarios. Pocos profesionales han antepuesto el interés de sus pacientes por delante de su patrimonio en la etapa más dura de la crisis o han asumido inversiones tecnológicas para poner al Sistema Nacional de Salud en la vanguardia con herramientas como la receta electrónica. Sin duda esto no significa que no haya que seguir trabajando por buscar la excelencia, pero también es justo reivindicar, al menos una vez al año, el trascendental papel que nuestro colectivo tiene para garantizar un sistema sanitario de calidad, eficiente y seguro en una sociedad que persigue el bienestar de su población. 